\title{
Food safety and nutrition - how to prepare for a challenging future? New approaches for using scenarios for policy-making
}

\author{
Anne-Katrin Bock ${ }^{1}$ (D) - Laurent Bontoux ${ }^{1}$ \\ Received: 27 July 2017 / Accepted: 18 November 2017 / Published online: 4 December 2017 \\ (C) The Author(s) 2017. This article is an open access publication
}

\begin{abstract}
Scenarios are a well-established methodology used in foresight. In this paper a three-phased process is described to maximise relevance for policy-making of a set of scenarios. As a first step, four scenarios were developed as a basis for the assessment of the ability of the EU's legislative and policy framework on food safety and nutrition to deal with possible future challenges. In the second step the scenarios were analysed by stakeholders to identify the scenario-specific challenge profiles in terms of food safety and nutrition. Policy and regulatory responses were formulated towards improving the fitness of the EU food framework for the future. The pertinence and realism of this exercise generated questions about how the role of the EU policy maker in this area could develop. To answer this question, in a third step, a new tailor-made approach was developed, allowing exploring and testing policy-making under diverse circumstances. The serious gaming platform, the Joint Research Centre's Scenario Exploration System, was adapted and applied with a number of selected stakeholders. Both approaches, each on their own, demonstrated the power of scenarios for simulating realistic policy circumstances. In combination, the process allowed to examine, in systemic way, different aspects of future policies and fostering a more forward-looking mind-set to inform practical policy-making.
\end{abstract}

Keywords Foresight $\cdot$ Scenarios $\cdot$ Serious game $\cdot$ Policy support $\cdot$ Nutrition $\cdot$ Food safety

\section{Background and policy context}

Food, in recent years, has seen a come-back to the top of the political agendas world-wide. The food price crisis of $2007 /$ 2008 demonstrated the vulnerability of the global food system. Megatrends such as increasing future demand for food due to a growing world population with expected growth in animal protein consumption, the expected negative impacts of climate change, probably leading to significant reductions in crop yields in some areas, combined with possible future scarcity of natural resources such as water, soil, biodiversity and mineral fertilisers are expected to exacerbate today's challenges for the food system [1].

While many see the sustainable production of sufficient food as a major challenge $[2,3]$, food safety and nutrition in terms of healthy diets are indispensable elements of food security. The

Anne-Katrin Bock

anne-katrin.bock@ec.europa.eu

1 European Commission, Joint Research Centre (JRC), Directorate Competences, Foresight, Behavioural Insights and Design for Policy Unit, Brussels, Belgium
World Health Organisation estimated that in 2010 about 600 million people have fallen ill because of unsafe food, and 420,000 died, a third being children under 5 years [4]. Furthermore, good nutrition has been identified as a prerequisite to meet 12 of the 17 Sustainable Development Goals, ${ }^{1}$ and unhealthy diets are contributing as one of the main, modifiable risk factors to the increasing burden of non-communicable diseases. ${ }^{2}$

In the EU, food policy, taking a 'farm to fork approach', aims at providing EU citizens with safe, nutritious, high quality and affordable food. General principles and requirements are laid down in the General Food Law [5]; many additional regulations cover specific aspects such as food contact materials, food additives etc. Although European citizens enjoy a high level of food safety, recent European and global food safety incidents show that it cannot be taken for granted (e.g. Bovine Spongiform Encephalopathy (BSE) epidemic starting 1986 in the UK, enterohemorrhagic (EHEC) Escherichia coli O104:H4 bacteria outbreak in Germany in 2011, adulteration of milk with melamine in China in 2008).

\footnotetext{
${ }^{1}$ WHO|United Nations Decade of Action on Nutrition: http://www.who.int/ nutrition/decade-of-action/en/

${ }^{2}$ World Health Organization: http://www.who.int/gho/ncd/en/
} 
Against the background of increasing levels of overweight and obesity [6], the EU in 2007 put forward the White Paper on a Strategy for Europe on Nutrition, Overweight and Obesity Related Health Issues [7]. An EU regulatory framework covering food labelling and marketing of food products is in place to enable informed food choices. Furthermore, nonlegal approaches are pursued, e.g. via the EU Action Plan on Childhood Obesity [8] or the EU Platform for Action on Diet, Physical Activity and Health, which under the leadership of the European Commission and in collaboration with industry and civil society organisations, aims at establishing different kinds of initiatives such as reformulations of food products to move towards healthier diet. ${ }^{3}$ Still, OECD projections indicate increasing levels of obesity towards 2030 [6].

The EU regularly carries out assessments of existing regulatory frameworks to make sure they are fit for purpose. ${ }^{4}$ This is in essence a backwards looking assessment to answer the question if the regulatory framework worked in the recent past. To have a framework in place that is able to deal with new challenges and opportunities this approach needs to be complemented with a forward looking exercise considering the possible long-term evolution of relevant trends and stakeholders and resulting implications. There exist several studies analysing possible implications for the capacity to produce enough food, while food safety and nutrition are less or not at all covered, although these are recognised as important characteristics of food security.

Furthermore, the food system involves many actors, from e.g. seed producers, farmers, food industry to retailers, restaurants and consumers, who all have a role to play in the production and consumption of healthy and safe diets. Therefore, any consideration of future developments and challenges need to be inclusive in terms of different relevant expertise and perspectives.

Foresight provides for a systematic, inclusive and systemic approach to analyse alternative future developments and their implications. ${ }^{5}$ With the aim to identify future possible challenges for food safety and nutrition in the EU, and to assess the preparedness of the EU legislative framework on food, the European Commission' Joint Research Centre (JRC), in close collaboration with the European Commission's Directorate General for Food Safety and Health, DG SANTE, carried out a foresight initiative between 2015 and 2016 .

This initiative, as will be described in the paper, evolved step by step. As a first step, a scoping study was commissioned by DG SANTE which identified relevant drivers of

\footnotetext{
$\overline{3}$ EU platform for action on diet, physical activity and health - European Commission: https://ec.europa.eu/health/nutrition_physical_activity/ platform_en

${ }^{4}$ European Commission: Refit - making EU law simpler and less costly, see http://ec.europa.eu/info/law/law-making-process/overview-law-makingprocess/evaluating-and-improving-existing-laws/reducing-burdens-andsimplifying-law/refit-making-eu-law-simpler-and-less-costly_en

${ }^{5}$ FOR-LEARN Online Foresight Guide: http://forlearn.jrc.ec.europa.eu/ index.htm
}

change and developed and analysed driver-specific-scenarios [9]. Recognising the need for more comprehensive scenarios, this exercise was followed up by an extensive foresight study carried out by the JRC, involving a broad range of stakeholders. Based on the scenarios and the discussions in the context of the study on the future food safety and nutrition policy in the EU, the question emerged if the role of the policy maker might also face some changes in the future. To approach that question we applied a tool developed by the JRC, the Scenario Exploration System.

This paper will describe how we developed and used scenarios to support these different aspects of EU food policies. The comprehensive outcomes of the foresight study, detailing the scenarios and the results of their analysis can be found in the respective JRC report [10].

\section{Developing tailor-made scenarios}

Scenario building is a well-established foresight methodology $[11,12]$. The scenarios, to be useful for answering the question on future preparedness of the EU legal framework on food safety and nutrition, needed to fulfil, apart from the basic criteria plausibility, consistency, and diversity, ${ }^{6}$ the following requirements:

- $\quad$ They need to be comprehensive, i.e. they are based on a combination of different, most relevant drivers of change and consider the whole food system.

- They need to be exploratory, i.e. they do not represent certain objectives for future development but rather answer the question 'what if?'

- They need to be challenging in terms of food safety and nutrition to be useful for future-proofing the regulatory framework. This means that positive scenarios in this sense were not used for the study.

The scenario development was based on a set of nine drivers (Global trade, EU economic growth, agro-food chain structure, technology update, social cohesion, food values, climate change, depletion if natural resources, and world population growth) derived from the scoping study [9] that were analysed to identify possible directions of future development.

In an internal workshop with JRC experts with different academic backgrounds and expertise, including but not limited to food safety and nutrition, the possible driver developments were explored regarding their implications for food safety and nutrition. Global trade (full globalisation vs fragmentation) and food values (differing primary motivations for food choice such as price, convenience vs health and /or

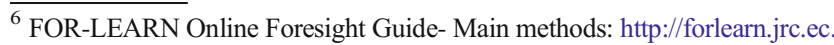
europa.eu/guide/4_methodology/meth_scenario.htm
} 
environmental impacts) were selected as starting points for the scenario development due to their significance for both food safety and nutrition. The remaining seven drivers were combined in a way that resulted in meaningful scenarios. A common background pressure on the food system was generated by assuming for all scenarios a similar, challenging development for environmental conditions (climate change and natural resource depletion) and food demand (growing world population). It was also assumed that the EU and its institutions as well as the current regulatory food-related infrastructure would remain in place.

The result of this exercise were four scenarios which were further developed by the project team and discussed, amended and agreed at a workshop by a group of ca. 35 stakeholders from the European Commission, academia, regulatory authorities, industry, and consumer organisations:

- Global food: globalised food chains and a further concentrated global food industry with a pre-dominance of highly processed convenience food

- Regional food: trade fragmentation, the EU moves towards a circular, self-sufficient economy with citizens actively involved in food production and high food prices

- Partnership food: a non-competitive EU teams up with an economically stronger partner while facing brain-drain and loss of technological know-how with predominance of highly processed convenience food

- Pharma food: the striving EU food industry is the global market leader in functional and pharmaceutical food, catering to the demand of personalised diets of very health aware, ageing citizens

Figure 1 summarises the scenario development and application process used in this project.

\section{Testing the resilience of EU food regulatory and policy framework}

Once the scenarios had been agreed, the workshop participants were asked to identify scenario-specific challenges for food safety and nutrition. Distributed in scenario groups they were tasked with answering the questions 'What can go wrong in the scenario in terms of food safety or nutrition?' and 'What are new or known but changed risks/hazards/challenges in the scenario?'.

In this process, 29 challenges were identified for the four scenarios, of which eight were shared by all scenarios (e.g. shortage of quality water or development of alternative food sources such as insect proteins); others were unique to specific scenarios. The results provided the project team with a rich challenge profile for each scenario. The four challenge profiles were further elaborated based on scientific literature as they were going to be used in a follow-up workshop.
For this second workshop, the profile of participants was enlarged to include persons with specific expertise in the EU food regulatory framework and its application. Participants were split in scenario-specific sub-groups and asked to prioritise the challenges identified in the first workshop according to importance. The objective was to be able to focus on the top six challenges per scenario for the rest of the workshop. The next task was to develop a narrative around this prioritised set of scenario-specific challenges, weaving them into the scenario context. The aim was to create vivid, plausible scenario-specific stories to tell to a 'policy panel'. Two four-person 'policy panels' were formed by workshop participants with strong legal and policy expertise. These 'policy panels' were challenged with the scenario-specific narratives around food safety and nutrition related problems in 2050 . The panel's task was to discuss the set of scenario-specific challenges and come up with policy options to address them, including any needs for legal changes. This exercise included an element of role play which contributed to the discussions being constructive and anchored in the future. Participants in the respective scenario groups then further discussed and enriched the advice given by the 'policy panels' to arrive at the end of the workshop with a set of concrete recommendations on how to face the upcoming challenges by scenario and to improve the fitness of the EU framework for the future.

As an example the narrative and panel response for the scenario Pharma food is given in Box 1. A similar output was achieved for the other three scenarios. These results were further analysed and developed by the project team and are presented in the final report of the study [10].

\section{BOX 1 Policy panel for the Scenario 'Pharma food'}

\section{The challenges}

The consumer in 2050 is confronted with a broad range of food products to choose from, available 24/7. Many of these products contain new ingredients with new functionalities, including pharmaceutically active components. Research has been very successful in providing the necessary knowledge for industry to develop these 'high tech' foods or 'Phoods', i.e. pharmaceutically active food. In addition, the mainstreaming of $3 \mathrm{D}$ printing equipment in European kitchens, allows for home-manufacturing of tailored food, using ingredients ordered and provided from individuals or companies from all over the world. 'Phood' is very much in demand to treat and prevent illnesses.

Supported by digital diet coaches, the consumer seems to be very much in control of his diet, but does everybody really understand what he or she is consuming? To make informed choices, the consumer in 2050 needs to be really well educated about nutrition and how it links to health. How do we achieve that and how to keep up in education with developments? The consumer also has to rely pretty much on the information that is provided by the few big players of the pharma-food industry. That gives the industry a very high responsibility to ensure the consumer chooses the right products and ingredients for his/her health - a considerable challenge given the plethora of ingredients available and used in combination, the huge amount of data with (are they sufficiently reliable?), the challenge of traceability of ingredients, and the difficulties for risk assessment. This translates also in challenges for the governance of the food system - how to limit the exposure of 
Fig. 1 The 3-step process of scenario development and application
1. Scenario development

-Adaptation and complementation of drivers from scoping study

-Determination of realistic value ranges for driver development

- Driver prioritisation (internal workshop)

- Development of scenario rationales (internal workshop)

- Development of four robust scenarios

-Enrichment and validation of scenarios (workshop with external stakeholders)

\section{Scenario analysis \& policy options}

-Identification of scenario-specific challenges for food safety and nutrition (workshop with external stakeholders)

- Refinement of scenario challenge profiles

- Prioritisation of challenges per scenario (workshop with external stakeholders)

-Development of policy options using 'policy panels' (workshop with external stakeholders)

\section{Scenario exploration on future roles of policy makers}

-Adaptation of the Scenario Exploration System (SES) platform using the food safety and nutrition scenarios

- SES session with stakeholders

-Plenary debriefing consumers to certain compounds? There might be the tendency by consumers to take more of a certain substance trying to boost its effects e.g. for memory improvement. How should maximum levels of daily intake be set and controlled? As the whole supply chain has changed, how can controls be effective? What regulation would be effective, and what balance between hard and soft law would be effective?

The policy panel's answer:

In this scenario the regulatory authorities will be outpaced by scientific developments, the industry and the consumer. The combined pressure of a different level of health claims for food products, many individual producers who are at the same time consumers and sellers, the global market for products and ingredients and the unknown role of a strong industry will need to be met by a strong science basis and a close look at the regulation. Definitions for food and pharmaceuticals will need to be revisited, and the best regulatory way forward (new or adaptation of existing regulation?) will need to be determined. Certifications for food $3 \mathrm{D}$ printers and diet counsellors including digital apps might need to be considered. Health insurances might play a role as well and health inequalities might emerge due to not being able to use high level ingredients or food producing machines. However, consumers also have a lot of common sense, and that might not change and could be relied on to some extent.

\section{Simulating possible future roles for EU policy makers}

The pertinence and realism of this first exercise generated questions about how an EU policy-maker such as DG SANTE would best play its future food policy role. Assessing the ability of the current EU food safety and nutrition regulatory framework to deal with possible future challenges and identifying its potential needs for evolution is essential. There might also be implications for the future role of EU policy makers, which against the background of any institutional strategies, are useful to explore.
Over the last 15 years, the EU regulatory and policy framework on food safety and nutrition was created. There is now a broad recognition that this institutional set-up has reached maturity [13] and, as the results of the foresight initiative show, that the legislative work that dominated the last 15 years and has shaped the role of the respective EU policy maker, might change in terms of focus and means in the coming decades. How are the policy-making demands likely to evolve under these conditions? Answering this question in sufficient depth required the development of a new, tailor-made approach.

As the previous scenario-based process had been perceived as delivering valuable results, also the reflection on the future role of the policy maker should be connected to these scenarios and their implicit challenges to food safety and nutrition.

A serious gaming platform, the JRC Scenario Exploration System (SES) [14] (Fig. 2), was used to bring the existing scenarios to life, allowing exploring and testing policy roles under diverse circumstances quickly and in a safe space. Furthermore, the SES allowed the EU food policy maker to play its policy role in realistic new circumstances while being confronted with the behaviour of its main stakeholders (industry and consumers) under the different constraints created by the contrasting scenarios.

The SES operates by engaging four participants to develop and take up roles to chart their own courses towards their longterm objectives. This is taking place under the judgement of a fifth person representing the public. Box 2 summarises the rules of the scenario exploration. In the course of a 3-h session, participants do this journey twice within contrasting scenarios, holding the same roles and pursuing the same objectives, but having scenario-specific resources determining the room for manoeuvre. This double journey allows participants to 
Fig. 2 JRC Scenario Exploration System

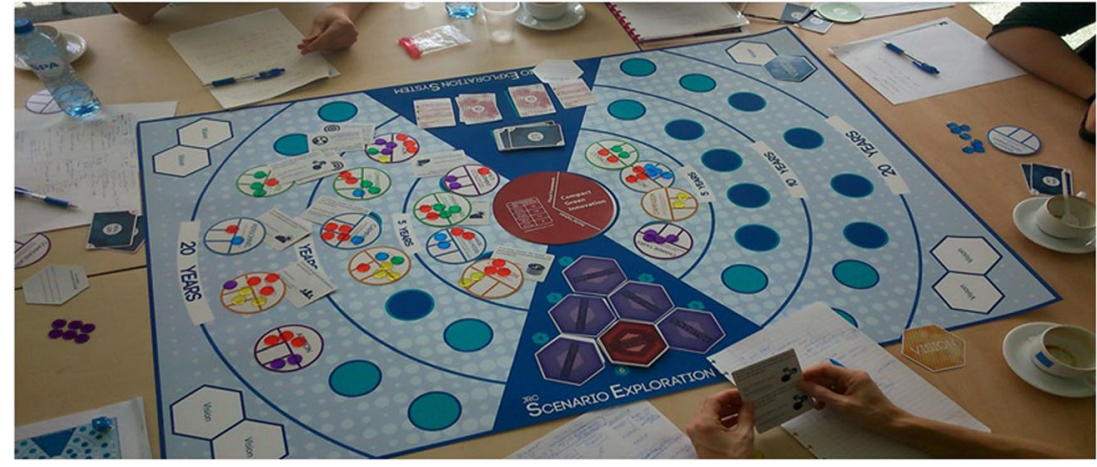

compare and contrast situations and potential solutions, leading to fruitful strategic discussions.

\section{BOX 2 Summary of the rules for the scenario exploration}

1. Participants take up a role (i.e. EU policy maker, multinational company, small or medium-sized company, civil society organisation, and a 'public voice' to judge the actions of the other 'scenario explorers') and develop it in enough detail.

2. The four scenario explorers determine their long-term vision, i.e. what they want to have achieved by the final time horizon (in this case 2050).

3. All scenario explorers are given scenario specific resources (a number of tokens) and a deck of 'action cards'. These are all the resources available to them for the three time steps to 2050 . They can take only one action per time step that they support with as much resources as they see fit.

4. The exploration master delivers a scenario specific narrative for the first time step. Scenario explorers take action in turn (highest die score starts). Once all have taken action, the public voice judges them and scores them with so-called impact tokens. Multiplying these impact tokens by the resources spent to support the action gives the scores for each action.

5. The second and third rounds follow a similar pattern as the first round but scenario explorers can now collaborate. Doing so allows them to benefit from the actions of others in addition to theirs. The exploration of the first scenario ends after the third round.

6. The process is repeated for the second, contrasting scenario. All participants keep the same roles and objectives but resources levels are adjusted to the new scenario.

A specific SES 'edition' was prepared, using the food safety and nutrition scenarios developed previously as a basis. The roles selected for this 'edition' were a large, multinational and a small food producing company, the EU food policy maker (i.e. DG SANTE) and a consumer organisation. As the SES starts its journeys in the present and leads participants towards the scenario endpoints in three time steps, an important part of the preparation work was to write the stories of how each of the scenarios could come about in three time steps. These stories for two contrasting scenarios, Global Food and Regional Food, are presented in Table 1.

A scenario exploration session was then organised with DG SANTE and their key stakeholders. The different roles (small and multinational food companies, consumer organisation and EU food policy maker) were taken by experienced professionals holding similar roles in real life. The chosen theme for the session was food innovation. The session was organised with two teams in parallel to be able to explore all four scenarios at the same time. The session was followed by a plenary debriefing with all participants. The purpose of this discussion was to capture the learnings and impressions from participants as well as to reflect on the process [14].

To illustrate how the SES session worked, the scenario exploration of two scenarios, Global food and Regional food, is described below.

The following fictitious roles were selected by the participants:

- EU food policy maker: 'DG SANTE'/European Commission. Its vision for 2050 is to ensure safe, nutritious, affordable food while ensuring that the food industry strives and is resource-efficient

- Large multinational food company: specialised in producing food ingredients such as proteins and vitamins targeting the 'health food' sector. Its long-term vision is to remain resilient and grow while continuing to provide safe, nutritious, sustainable food ingredients to feed a growing world population.

- Small food company: a small cheese producer. Its longterm vision is to survive (remain competitive) by meeting consumer demands, and bringing new products on the market using its regional and traditional way of production.

- Civil society organisation: an EU consumer organisation. Its long-term vision is to ensure the public's access to safe food and an informed choice, and to support food innovation only in case of a clear consumer benefit.

The following describes the "events" that took place in the scenario journeys at the various time horizons.

\section{Scenario Global Food 2020}

With current trends continuing in terms of environment, social inequalities and industry concentration, the multinational company starts a heavy long-term investment plan to develop new sources for raw materials, while the EU policy maker initiates and puts its weight behind EU level discussions on how to reduce food waste. Both actions have a positive echo 
Table 1 Timeline of the stories used to explore the scenarios Global Food and Regional Food with the SES

Scenario GLOBAL FOOD

2020 1. Global population and global trade continue to grow

2. Climate change impacts worsen steadily

3. Increased pressure on natural resources

4. Social protection systems weaken

5. EU citizens become more open towards modern food technologies

6. Concentration of agro-food sector continues

2030 1. EU global economic power weakens, global trade rules simplified

2. International food companies can secure resources at global level

3. Traditional food values weaken, cost-cutting in food production

4. Growing urbanisation and higher demand for processed convenient food

5. More investments in modern food preservation

6. High socio-economic inequalities reflected in public health

2050 1. Fully liberalized global trading system

2. Global food industry concentrated in few multinationals

3. New technologies readily taken up to address climate change and resource scarcity

4. Fully globalised and commoditised food chain

5. Diets mostly market driven

6. Quality, fresh foods only available to those who can afford them
Scenario REGIONAL FOOD

1. Global population and global trade continue to grow

2. Increased pressure on natural resources world-wide

3. No effective progress at international level to stop climate change

4. More environmental awareness and vocal citizen groups

5. Citizens perceive EU as an important actor to defend their interests

6. Selected acceptance of new food technologies, ICTs permeate all sectors

1. Frequent trade disruptions raise awareness on food supply security

2. More incidences with quality and safety of imported food

3. Higher food prices increase share in household expenditure considerably

4. More alternative food chains start to develop, including home-grown food

5. Citizens are increasingly critical of business as usual

6. Modern food technology starts being accepted for sustainability of quality food production

1. The EU, as others, selectively abandoned trade agreements

2. The EU economies are becoming largely circular and self-reliant

3. EU food chains are largely local/regional with urban farming \& home-grown food

4. Sustainability is promoted through taxes and regulations

5. citizen initiatives make up for reductions in social services

6 . Food is valued, animal protein in diets has been reduced considerably in the public and bear some fruits. The small cheese producer feels the stronger competition and invests to modernise its infrastructure. This helps it survive the coming years. The EU consumer organisation cautiously moves into digital support tools for consumers to help them find their way towards value for money products. This is taken up in some countries.

\section{0}

The advance of new technologies and the steady trend towards more convenience food leads the multinational ingredient producer to seek closer collaboration with food companies rooted in local markets and offer collaboration to SMEs. Unfortunately the collaboration with the cheese producer does not lead to the products that consumers like. Meanwhile the policy maker and the consumer organisation see the need to support consumers in their choice for quality food. The consumer organisation invests in developing a quality label that fails to be taken up by industry and has little follow up with consumers. The EU policy maker considers legislation to oblige industry to provide some quality versions of convenience food. This has limited success since consumers cannot be forced to buy these products.

\section{0}

EU consumers move further towards low-cost convenience food and the cheese producer decides to go with the tide, move away from traditional products and produce new, cheaper and tastier products. This helps the company to survive. The EU policy maker wants to combat the lack of affordable fresh produce; it pushes for taxes on the large convenience-food producers to increase public budgets and support specifically primary production and fresh produce. This move is supported by the multinational company that sees this as an opportunity to get more attention and market shares for their healthy ingredient products that had not been very successful in the past. The consumer organisation still tries to develop tools to better inform consumers. However, given the framework conditions, these do not take off.

In the end, the multinational company does not achieve its longterm vision but stays in the game due to collaborations with the other stakeholders. The policy maker has some influence due to active involvement in the market with (heavy) legislation. The SME survives with a change of product portfolio, while the consumer organisation has lost contact to its clients.

The participants then explored the contrasting 'Regional Food' scenario.

\section{Scenario Regional Food 2020}

The environmental constraints grow while citizens are becoming more concerned and more active on this. The small cheese producer reacts with heavy investment in $R \& D$ to make processes more resource efficient. The multinational company puts much emphasis on showing local presence and improves links to local food enterprises. The growing engagement of citizens in food is supported by the consumer organisation through a new platform to link the local community and allow 
exchange of experiences, goods etc. This is taken up enthusiastically. The EU policy maker has some concern regarding the increasing involvement of individuals in food production and runs a small, but not very visible campaign to increase awareness of food safety issues and legislation.

\section{0}

As global trade becomes more volatile and thus less reliable, local production gains importance. A few food scares from imports further add to this trend, although the EU policy maker tries to restore trust in imports with better standards and stricter enforcement. This is supported by all stakeholders. The EU policy maker is following a diversified approach, supporting and collaborating with the initiatives supporting local production. At the same time the small food producer successfully lobbies the regulator to obtain acceptance of better production methods. The multinational company buys into this and sees it as an element of its new business approach creating stronger partnerships with local companies to secure its presence on the EU markets. As citizen engagement in food production continues to grow, the consumer organisation steps up its support, facilitating the joint purchasing of infrastructure and machines for cooperatives.

\section{0}

The share of small scale, local food production is significant and the consumer organisation continues to support urban production with information and services (e.g. testing soil quality, training, etc.). This is very much taken up and supported by the EU policy maker as well as by small enterprises. The EU also invests in $R \& D$ to further improve the sustainability of small scale production. On the business side the multinational company decides to go fully local and to split up into many SMEs located in different EU regions. At the same time, the small cheese producer looks for collaboration with like-minded enterprises to increase performance.

In this scenario the multinational company could not find a way to convince other businesses that its products and organisation were useful in the constraints that this world faces. All other stakeholders faired very well. The SME prospered and reached out, the consumer organisation provided what consumers were looking for and pushed the trend further, while the EU policy maker achieved its vision through a mix of legislation and broad collaboration.

\section{Discussion and conclusion}

While there was a clear intention from the start to engage in a foresight exercise, the overall process described here was not designed as such from the start. Interest in going further emerged at the end of every step in view of the success achieved so far and of the need to understand more every time. The expertise available at the JRC made it possible to develop novel approaches on demand and to innovate 'on the go'.

In this process scenarios played a central role. Being a classic foresight tool, scenarios as developed and applied in this study confirmed again their usefulness in facilitating discussions on possible future developments and the implications. Providing easy access to different futures while offering comprehensiveness through the combination of many different drivers, they enabled targeted discussions on possible future challenges. The analytical format we developed and tested within the context of workshops, matching expert knowledge with creative elements and role play turned out to be an efficient approach for the development of future-oriented, actionable policy recommendations. An additional important element for this was the involvement of a broad range of stakeholders, ensuring the incorporation of different perspectives in the scenarios, discussions and results. Key in this respect was the ability to recruit participants with high levels of relevant expertise on all the aspects of the issues at stake. In particular the participation of EU policy makers, especially those directly interested in the outcomes of the study, was relevant as this is a pre-condition for buy-in and subsequent take-up of results [15].The very high level of competence of the members of the 'policy panels' also ensured the quality of the output.

The JRC Scenario Exploration System represents a different approach to using scenarios. Combining a board game with role play, it is characterised by the realism of the conversations, which take place in a relaxed, playful though serious atmosphere with the future as a 'safe space'. Being a resource constrained actor pursuing its own objective in the context of scenarios while interacting with other stakeholders engages participants into taking many elements into account simultaneously in a dynamic way. In effect, they engage into systemic thinking without realising. The time horizon used (2050) and the presentation of a set of relevant megatrends at the start of the session also helped participants take a long-term perspective.

Exploring contrasting scenarios in sequence also allows to compare the two paths and to reflect on the reasons for the differences in outcomes. This gives an additional depth to the analysis. The exercise also helps realise both the importance of the general context in constraining the behaviour of the stakeholders, but also their own freedom and ability to deal with what happens. The SES provides a very time-efficient way of engaging stakeholders in constructive discussions on possible future strategies.

However, the overall quality of the process depends heavily on two parameters: the quality of the scenarios and the contributions of the participants. The set of scenarios is the backbone of the process and any shortcomings of the 
scenarios will limit its usefulness. For example, missing relevant trends and drivers, neglecting plausible trend reversals, or excluding important actors in the system will lead to incomplete scenarios and thus to a lack of relevant perspectives in their exploration and analysis.

The quality of the process is also very much dependent on one's ability to 'capture' the right participants. A lower quality of participants would undoubtedly result in a lower quality of output. For this reason, significant effort was made to identify the right participants, both in terms of ensuring the diversity and balance of relevant stakeholders and of bringing in the best possible level of expertise. Efforts were also made to make participation attractive. The process was positioned as an innovative approach to EU policy making, its objectives were made clear and its intended impact was transparent. The target audience was also mostly among the classic stakeholders of DG SANTE, allowing for a level of personal interaction that created trust. Once the process had started, satisfaction with every completed step and transparency around the results also ensured willingness to participate in subsequent steps.

An unavoidable limitation inherent to the process is the need for simplification to make the process workable. Examples are the need to reduce the number of challenges per scenario to six in the second workshop and the different simplifications applied in the Scenario Exploration System to make scenario explorations possible in a 3 -h time frame (e.g. only one 'public voice' and only 4 scenario explorers). Another point of possible criticism resides in the scoring system of the SES, which can be seen as very crude when compared to real life situations, but which is important to create desirable dynamics between the participants during the sessions (e.g. resource constraints).

Furthermore, the need to choose a theme for a SES session (in this case food innovation) also closely links the resulting analysis to this theme. Validity of results beyond this framework would need to be explored with additional SES sessions choosing other themes related to other aspects of food policy.

Overall, the following conclusions can be drawn:

This initiative confirms the well-known fact that scenarios are powerful tools for foresight. Here, scenarios have been used successfully through two very different approaches with a wide range of stakeholders to generate a collective understanding of alternative futures and to formulate realistic responses. When used in the right setting, scenarios are a very powerful tool to help people think systemically with a longterm perspective.

There is a high added value of engaging in an inclusive and participatory exercise involving a wide range of stakeholders and perspectives. Civil society organisations, industries, policy makers and researchers were represented in their diversity through competent participants. This led to a lot of cross- fertilisation and to participants learning from each other when looking at the scenarios from different perspectives.

What made this study a compelling exercise was the combination of approaches used: the three-step process made it possible to go beyond the powerful immersive experience provided by scenarios to enhance one's own systemic thinking, and to get into practical policy making. The process could also range from policy recommendations at the scale of EU food policy (Workshop 2) to more specific reflections linked to narrower issues (SES session).

Considering the time needed to carry out a full-fledged scenario building exercise and to run a large scale participatory workshop, the overall duration of the process of about 24 months remained reasonable.

Last but not least, this process could be applied to any policy domain. If adequate scenarios are available (and many are), this process could be run in the time needed to organise one workshop and write up its report in terms of identification of challenges and policy recommendations. Also the SES can be quite easily adapted to other scenarios. The SES is already available to all under a creative commons licence. Two different versions (including the food safety and nutrition version) are available ${ }^{7}$ and several more are being developed.

Publisher's note Springer Nature remains neutral with regard to jurisdictional claims in published maps and institutional affiliations.

\section{Compliance with ethical standards}

Disclaimer The views expressed here are those of the authors and do not necessarily reflect the views of the European Commission.

Open Access This article is distributed under the terms of the Creative Commons Attribution 4.0 International License (http:// creativecommons.org/licenses/by/4.0/), which permits unrestricted use, distribution, and reproduction in any medium, provided you give appropriate credit to the original author(s) and the source, provide a link to the Creative Commons license, and indicate if changes were made.

\section{References}

1. FAO (2017) The future of food and agriculture - trends and challenges. Rome. http://www.fao.org/3/a-i6583e.pdf. Accessed 26 July 2017

2. FAO (2009) How to feed the world in 2050. FAO Headquarters, Rome

3. Foresight (2011) The future of food and farming: challenges and choices for global sustainability. Final Project Report. The Government Office for Science, London

4. WHO (2015) WHO estimates of the global burden of foodborne diseases: foodborne disease burden epidemiology reference group 2007-2015. http://www.who.int/foodsafety/publications/ foodborne_disease/fergreport/en/. Accessed 26 July 2017

\footnotetext{
${ }^{7}$ European Commission: Scenario Exploration System (SES), see: https://ec. europa.eu/jrc/en/research/foresight/ses
} 
5. REGULATION (EC) (2002) No 178/2002 of the European Parliament and of the Council of 28 January 2002 laying down the general principles and requirements of food law, establishing the European Food Safety Authority and laying down procedures in matters of food safety. Off J Eur Communities L 31:1-24

6. OECD (2017) Obesity Update 2017. https://www.oecd.org/els/ health-systems/Obesity-Update-2017.pdf. Accessed 26 July 2017

7. European Commission (2007) WHITE PAPER ON A Strategy for Europe on Nutrition, Overweight and Obesity related health issues. COM (2007) 279 final, Brussels

8. European Union (2014) EU action plan on childhood obesity 20142020. $24022014 \mathrm{https} / /$ ec.europa.eu/health/sites/health/files/ nutrition physical activity/docs/childhoodobesity actionplan 2014_2020_en.pdf. Accessed 26 July 2017

9. European Commission (2013) Scoping study Delivering on EU food safety and nutrition in 2050 - Scenarios of future change and policy responses. Final Report. https://ec.europa.eu/food/sites/food/ files/safety/docs/final report scoping study en.pdf. Accessed 26 July 2016

10. Mylona K, Maragkoudakis P, Bock AK, Wollgast J, Caldeira S, Ulberth F (2016) Delivering on EU food safety and nutrition in 2050
- future challenges and policy preparedness. Publications Office of the European Union doi: https://doi.org/10.2787/625130 (online)

11. Schwartz P (1991) The art of the long view. Currency Doubleday, New York

12. Popper R (2008) Foresight methodology. In: Georghiou R, Cassingena Harper J, Keenan M, Miles I, Popper R (eds) The handbook of technology foresight. Edward Elgar, Cheltenham, pp 44-88

13. Alemanno A (2014) Introduction: foundations of EU food law and policy. In: Alemanno A, Gabbi S (eds) Foundations of food law and policy - ten years of the European food safety authority. Routledge, Oxford, pp 1-14

14. Bontoux L, Bengtsson D, Rosa A, Sweeney JA (2016) The JRC scenario exploration system - from study to serious game. J Futur Stud 20(3):93-108. https://doi.org/10.6531/JFS.2016.20(3).R93

15. Cox A, Swift S, Rhisiart M (2015) Success factors for achieving policy impact in foresight studies. European Risk Observatory, European Agency for Safety and Health at Work. https://doi.org/ $10.2802 / 89572$ 